\title{
PENGENALAN SOIL INVESTIGASI UNTUK SISWA SMK BANGUNAN SEBAGAI DASAR PENGETAHUAN DESAIN PONDASI
}

\author{
Susy Srihandayani ${ }^{1}$, Desyanti ${ }^{2}$ \\ 1,Program Studi Teknik Sipil, Sekolah Tinggi Teknologi Dumai \\ 2,Program Studi Teknik Informatika, Sekolah Tinggi Teknologi Dumai \\ e-mail: gadisoil79@gmail.com
}

\begin{abstract}
This Community Service Program (PPM) partners with SMK Negri 02 Building Construction Department in Dumai City. This community service program is very important to be implemented, in order to be able to increase knowledge of soil investigation for students who will complete their education and will continue their education or who will work in the construction world. This is related to the limitations of facilities and infrastructure so that students only get basic knowledge about the types of foundation types without knowing earlier the process to design the foundation. Basic knowledge is very important for female students in the learning process which must then be applied in direct practice so that the knowledge obtained is easier to apply in the field. So the purpose of this community service program is to help provide additional knowledge and skills using equipment commonly used for Investigation Soil such as Hand Bor and Sondir (DCPT) capacity of 2.5 tons. From the test results in the field it is expected that students can also do data processing using computer programs or applications. With the implementation of this community service program, the community service implementation team, especially the Civil Engineering Geotechnical and Informatics Engineering Study Program, Dumai College of Technology provides skills on how to use tools, data processing and application to find out the type and design of a foundation.
\end{abstract}

Keywords - Soil Investigation, DCPT, Foundation, Hand Bor

\begin{abstract}
Abstrak
Program Pengabdian Masyarakat (PPM) ini bermitra dengan SMK Negeri 02 Jurusan Konstruksi Gedung di Kota Dumai. Program pengabdian masyarakat inisangat penting untuk dilaksanakan, agar dapat menambah pengetahuan penyelidikan tanah bagi siswa yang akan menyelesaikan Pendidikan dan akan melanjutkan pendidkan atau pun yang akan bekerja di dunia konstruksi. Hal ini berkaitan dengan keterbatasan sarana dan prasarana sehingga siswa hanya mendapatkan pengetahuan dasar mengenai jenis jenis pondasi tanpa mengenal lebih awal proses untuk mendisain pondasi. Pengetahuan dasar sangat penting dimiliki oleh siswa siswi dalam proses pembelajaran yang kemudian harus diterapkan kedalam praktek langsung agar ilmu yang diperoleh lebih mudah untuk di terapkan di lapangan. Jadi tujuan dari program pengabdian masyarakat ini adalah membantu memberikan pengetahuan tambahan dan keterampilan menggunakan peralatan yang umum digunakan untuk Soil Investigasi seperti Hand Bor dan Sondir (DCPT) kapasitas 2.5 Ton. Dari hasil pengujian dilapangan diharapkan siswa juga dapat melakukan pengolahan data menggunakan program computer atau aplikasi. Dengan terlaksananya program pengabdian masyarakat ini, tim pelaksana pengabdian kepada masyarakat khususnya Program Studi Teknik Sipil Geoteknik dan Teknik Informatika Sekolah Tinggi Teknologi Dumai memberikan skill tentang cara penggunaan alat, pengolahan data dan penerapan untuk mengetahui jenis dan disain sebuah pondasi.
\end{abstract}

Kata kunci-Penyelidikan Tanah, Sondir, Pondasi.

\section{PENDAHULUAN}

SMK Negeri 02 Berada Di Jl. Jakolin Bukit Datuk Lama Kecamatan Dumai Selatan, Merupakan salah satu sekolah Kejuruan Di Kota Dumai. SMK Negeri 02 memiliki beberapa jurusan diantaranya Teknik Gambar Sipil Arsitektur (TGSA), Teknik Konstruksi Gedung (TKG), Teknik 
Geomatika (TGEO), Teknik Audio Video (TAV) Teknik Elektronika Industri (TEI) Teknik Instalasi Tenaga Listrik (TITL), Teknik Pendingin Dan Tata Udara (TPTU), Teknik Komputer Dan Jaringan ( TKJ ), Teknik Pemesinan ( TP ), Teknik Pengelasan (TLAS), Teknik Kendaraan Ringan ( (TKR), Teknik Sepeda Motor (TSM), Honda Teknik Alat Berat Coop. PT. Trakindo, Dan Teknik Fabrikasi Logam.

Dari hasil survey dan wawancara yang dilakukan kepada Kepala Sekolah SMK Negeri 02 Dumai khususnya Jurusan Teknik Konstruksi Gedung terdapat mata pelajaran Struktur Bangunan yang diajarkan guru bidang studinya, tetapi karena keterbatasan ada beberapa pengetahuan dasar yang belum diberikan ke siswa terkait dengan pengetahuan struktur pondasi yang telah dipelajari.

Pengetahuan dasar sangat penting di miliki siswa siswi dalam proses pembelajaran yang kemudian harus diterapkan kedalam praktek langsung agar ilmu yang didapat lebih bermanfaat untuk dunia kerja. Solusi yang diberikan untuk para siswa dan siswi SMK Negeri 02 adalah dengan memberikan wawasan yang lebih rinci mengenai tujuan penyelidikan tanah dasar menggunakan peralatan Sondir dan Hand Bor untuk mengetahui jenis tanah dan karakternya untuk mengetahui jenis pondasi yang cocok untuk sebuah bangunan. Selain itu siswa siswi akan lebih memahami mata pelajaran yang selam ini diajarkan oleh guru bidang studinya dan memberikan pengetahuan dasar penggunaaan aplikasi untuk pengolahan data dari hasil pengujian di lapangan.

\section{METODE}

Metode pelaksanaan pada pengabdian masyarakat (PPM) adalah mengadakan pembelajaran secara teori dan praktek mengenai penggunaan alat penyelidikan tanah di lapangan berupa Sondir dan hand Bor, dan mempelajari secara umum mengenai cara pengolahan data hasil lapangan menggunakan aplikasi ataupun dengan Microsoft Excell.

Proses pelaksanaan pelatihan antara lain:

1. Pelaksanaan pelatihan berupa pengenalan alat dan prosedur penggunaan alat Sondir dan Hand Bor berupa ceramah/ penjelasan di depan kelas.

Sebelum praktek penggunaan alat di lapangan, Tim PPM memberikan penjelasan secara ringkas mengenai pengertian tanah, jenis tanah, klasifikasi tanah serta pengenalan jenis jenis pondasi berdasarkan karakteristik tanah. Selain itu juga siswa dibekali dengan pengetahuan tujuan melakukan Soil Investigasi.

2. Pelaksanaan Praktek di Lapangan

Pelaksanaan praktek penggunaan alat dilaksanakan di lapangan sekolah SMK Negeri 02 Dumai. Materi pelatihan di berikan oleh tim PPM, dengan lama kegiatan 120 Menit.

Materi pelatihan meliputi :

a. Pemberian teori dan pemahaman tentang penggunaan alat sondir dan handbor serta tujuan penggunaannya.

Dengan memberikan gambaran dan pemahaman tujuan menggunakan alat dasar untuk penyelidikan di lapangan diharapkan siswa dapat menerapkan di dunia lapangan kerja yang berhubungan dengan pembangunan konstruksi.

b. Pemberian penjelasan cara penggunaan alat Sondir dan Hand Bor

c. Menjelaskan cara pengolahan data hasil penyelidikan lapangan menggunakan aplikasi atau menggunakan Microsoft Excel.

\section{HASIL DAN PEMBAHASAN}

Pelaksanaan kegiatan PPM dengan judul "Pengenalan Soil Investigasi untuk Siswa SMK Bangunan Sebagai Dasar Pengetahuan Desain Pondasi" telah selesai dilakukan. Berikut ini merupakan hasil yang dicapai dalam pengabdian ini. 
Tabel 1. Hasil Pencapaian Pengabdian

\section{Persiapan}

\begin{tabular}{llll}
\hline \multicolumn{1}{c}{ Langkah } & \multicolumn{2}{c}{ Tujuan } & Hasil \\
\hline $\begin{array}{l}\text { Pembentukan Panitia } \\
\text { Kegiatan }\end{array}$ & $\begin{array}{l}\text { Membuat Struktur } \\
\text { Kepanitiaan } \\
\text { Pembagian Tugas dan }\end{array}$ & $\begin{array}{l}\text { Struktur terdiri dari tim dosen STT } \\
\text { Dumai }\end{array}$ \\
\hline Administrasi kegiatan & $\begin{array}{l}\text { Mengelola kegiatan dan } \\
\text { bukti pelaksanaan } \\
\text { pengabdian }\end{array}$ & $\begin{array}{l}\text { Daftar hadir peserta dan } \\
\text { tim dosen, modul kegiatan dan } \\
\text { berita acara pelaksanaan } \\
\text { kegiatan pengabdian }\end{array}$ \\
\hline $\begin{array}{l}\text { Pembuatan modul } \\
\text { pelatihan }\end{array}$ & $\begin{array}{l}\text { Membuat modul untuk } \\
\text { peserta dan sebagai bahan } \\
\text { presentasi }\end{array}$ & $\begin{array}{l}\text { Materi pelatihan : } \\
\text { Pengenalan Soil Investigasi } \\
\text { untuk Siswa SMK Bangunan } \\
\text { Sebagai Dasar Pengetahuan } \\
\text { Desain Pondasi }\end{array}$ \\
\hline
\end{tabular}

Pelaksanaan

\begin{tabular}{|c|c|c|}
\hline Langkah & Tujuan & Hasil \\
\hline $\begin{array}{l}\text { Pelaksanaan Pelatihan } \\
\text { Penggunaan Alat Sondir } \\
\text { dan Handbor }\end{array}$ & $\begin{array}{l}\text { Mengetahui dasar untuk } \\
\text { merencanakan pondasi } \\
\text { sesuai dengan } \\
\text { karakteristik tanah }\end{array}$ & $\begin{array}{l}\text { Siswa mampu mengoperasikan } \\
\text { alat Sondir dan Handbor }\end{array}$ \\
\hline \multicolumn{3}{|l|}{ Penutup } \\
\hline Langkah & Tujuan & Hasil \\
\hline Evaluasi kegiatan & $\begin{array}{lr}\text { Mengetahui } & \text { hal-hal } \\
\text { yang } & \\
\text { dianggap } & \text { perlu } \\
\text { untuk } & \text { perbaikan } \\
\text { kedepannya } & \\
\end{array}$ & $\begin{array}{lr}\text { Saran untuk } & \text { perbaikan } \\
\text { kegiatan } & \text { pengabdian } \\
\text { selanjutnya } & \end{array}$ \\
\hline Laporan kegiatan & $\begin{array}{l}\text { Melaporkan } \\
\text { Serangkaian Kegiatan } \\
\text { Pengabdian }\end{array}$ & Laporan kegiatan PPM \\
\hline
\end{tabular}

Kegiatan Pengabdian ini telah dilaksanakan pada hari jum'at, 27 Juli 2018 dengan jumlah peserta 48 orang terdiri dari 39 orang siswa SMKN 02 Dumai, 5 Orang guru SMKN 02 Dumai dan 3 orang Dosen Sekolah Tinggi Teknologi (STT) Dumai. Kegiatan ini diisi dengan pemaparan materi pelatihan oleh ketiga dosen Sekolah Tinggi Teknologi (STT) Dumai tentang pengetahuan dasar Penyelidikan Tanah /Soil Investigasi, Siswa dan Siswi sangat antusias dalam mengikuti pelatihan tersebut karena menambah pengetahuan mereka tentang dasar Soil Investigasi , setalah diberikan materi pelatihan siswa / siswi SMKN 02 Dumai yang didampingi oleh bapak / ibu guru diberikan praktek langsung bagaimana cara menyondir berdasarkan jenis tanah yang dilakukan di lapangan SMKN 02 Dumai. Dengan adanya praktek langsung siswa / siswi SMKN 02 Dumai menjadi lebih paham dalam menggunakan alat sondir dengan benar sesuai dengan standar operasional prosedur (SOP) yang berlaku.

Materi disampaikan oleh dosen Sekolah Tinggi Teknologi Dumai dan diakhiri dengan tanya jawab dari Siswa / Siswi SMKN 02 Dumai serta melakukan praktek langsung cara menggunakan sondir dan hand bor. 
Proses pelaksanaan dapat dilihat pada gambar sebagai berikut :

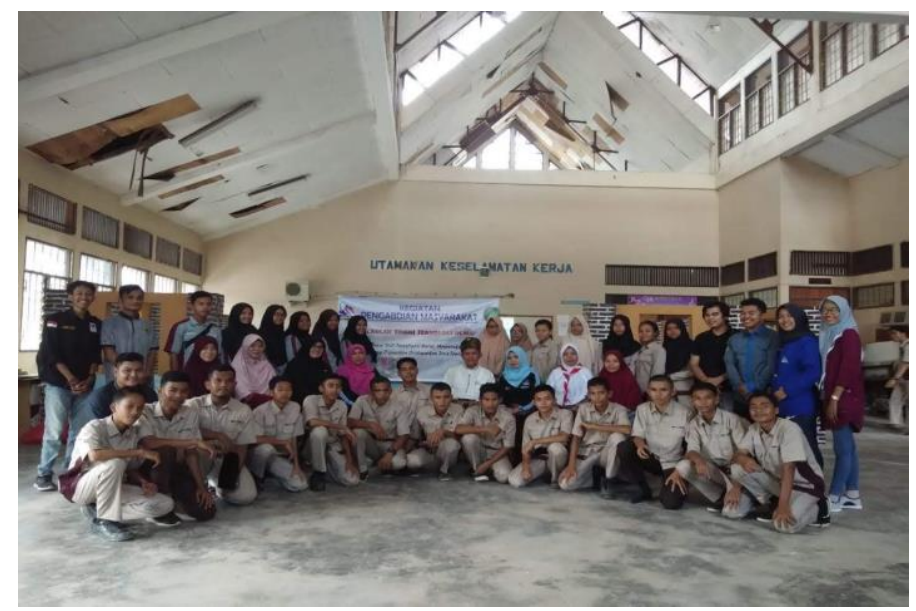

Gambar 1. Peserta Pelatihan Pengenalan Soil Investigasi untuk Siswa SMK Bangunan Sebagai Dasar Pengetahuan Desain Pondasi

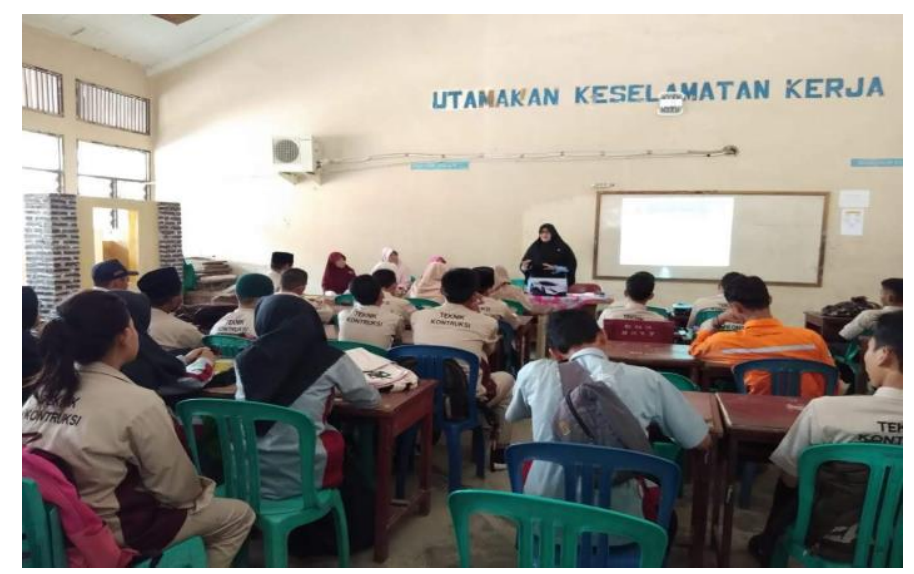

Gambar 2. Pemberian Materi Pelatihan Pengenalan Soil Investigasi untuk Siswa SMK Bangunan Sebagai Dasar Pengetahuan Desain Pondasi

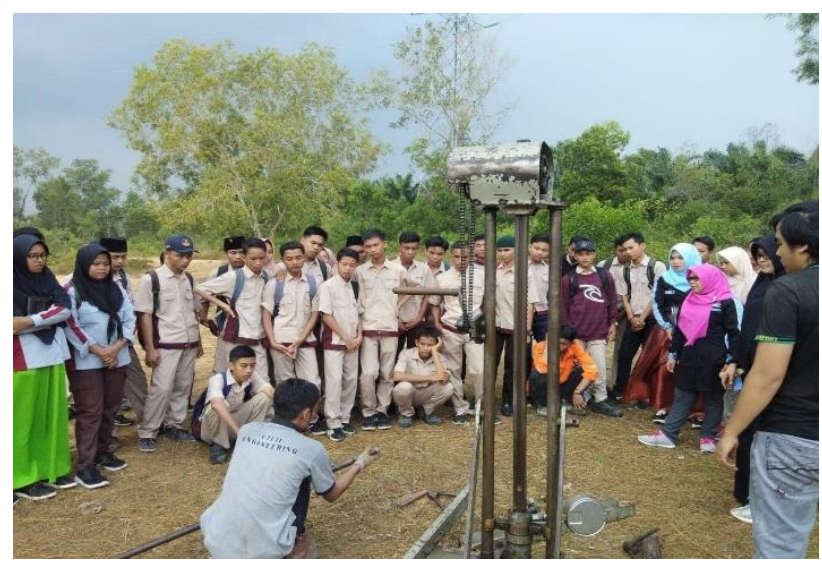

Gambar 3. Praktek Pengenalan Dasar Soil Investigasi Untuk Menentukan Jenis Pondasi yang Digunakan Berdasarkan Jenis Tanah

\section{KESIMPULAN}

Dengan dilakukannya kegiatan pelatihan ini diharapkan siswa dan siswi SMK Negeri 2 jurusan Bangunan, untuk mempelajari mata pelajaran struktur dalam mendisain pondasi sudah mengetahui karakteristik tanah dan mendisain sebuah pondasi yeng cocok berdasarkan jenis tanah. 
Kedepannya setelah menyelesaikan studi, bekerja di dunia konstruksi khususnya di bidang Geoteknik dapat mengimplementasikan ilmu dasar soil investigasi di lapangan.

\section{SARAN}

Pengabdian ini diharapkan dapat dilaksanakan setiap tahunnya untuk siswa SMK yang telah mempelajari mata pelajaran Struktur.

\section{UCAPAN TERIMA KASIH}

Penulis mengucapkan terima kasih kepada Pimpinan Sekolah Tinggi Teknologi Dumai yang telah memberi dukungan financial terhadap pengabdian ini.

\section{DAFTAR PUSTAKA}

[1] Hakam. A 2008, Rekayasa Pondasi Untuk Mahasiswa dan Praktisi, Padang

[2] Bowles, J.E., 1992, Analisis dan Desain Pondasi Jilid 1, Erlangga

[3] Srihandayani S, 2018, Modul Praktikum Mekanika Tanah Program Studi Teknik Sipil Sekolah Tinggi Teknologi Dumai 